\title{
Quasiphase matched surface emitting second harmonic generation in periodically reversed asymmetric GaAs/AIGaAs quantum well waveguide
}

\author{
Citation for published version (APA): \\ Fiore, A., Beaulieu, Y., Janz, S., McCaffrey, J. P., Wasilewski, Z. R., \& Xu, D. X. (1997). Quasiphase matched \\ surface emitting second harmonic generation in periodically reversed asymmetric GaAs/AIGaAs quantum well \\ waveguide. Applied Physics Letters, 70(20), 2655-2657. https://doi.org/10.1063/1.118987
}

DOI:

$10.1063 / 1.118987$

Document status and date:

Published: 01/01/1997

Document Version:

Publisher's PDF, also known as Version of Record (includes final page, issue and volume numbers)

\section{Please check the document version of this publication:}

- A submitted manuscript is the version of the article upon submission and before peer-review. There can be important differences between the submitted version and the official published version of record. People interested in the research are advised to contact the author for the final version of the publication, or visit the $\mathrm{DOI}$ to the publisher's website.

- The final author version and the galley proof are versions of the publication after peer review.

- The final published version features the final layout of the paper including the volume, issue and page numbers.

Link to publication

\footnotetext{
General rights

- You may freely distribute the URL identifying the publication in the public portal. follow below link for the End User Agreement:

www.tue.nl/taverne

\section{Take down policy}

If you believe that this document breaches copyright please contact us at:

openaccess@tue.nl

providing details and we will investigate your claim.
}

Copyright and moral rights for the publications made accessible in the public portal are retained by the authors and/or other copyright owners and it is a condition of accessing publications that users recognise and abide by the legal requirements associated with these rights.

- Users may download and print one copy of any publication from the public portal for the purpose of private study or research.

- You may not further distribute the material or use it for any profit-making activity or commercial gain

If the publication is distributed under the terms of Article 25fa of the Dutch Copyright Act, indicated by the "Taverne" license above, please 


\title{
Quasiphase matched surface emitting second harmonic generation in periodically reversed asymmetric GaAs/AIGaAs quantum well waveguide
}

\author{
A. Fiore, ${ }^{\text {a) }}$ Y. Beaulieu, ${ }^{\text {b) }}$ S. Janz, J. P. McCaffrey, Z. R. Wasilewski, and D. X. Xu \\ Institute for Microstructural Sciences and Solid State Optoelectronics, Consortium, National Research \\ Council, Ottawa, Ontario K1A OR6
}

(Received 3 January 1997; accepted for publication 20 March 1997)

\begin{abstract}
We experimentally demonstrate surface-emitting second harmonic generation in a waveguide containing asymmetric coupled GaAs/AlGaAs quantum wells. The nonlinear conversion efficiency is enhanced by reversing the asymmetric well orientation every coherence length, in order to quasiphase match the vertical second harmonic generation process. The measured spectrum of the asymmetric quantum well susceptibility is dominated by an excitonic peak at a pump frequency corresponding to half of the first electron-heavy hole transition energy. (C) 1997 American Institute of Physics. [S0003-6951(97)03320-2]
\end{abstract}

Nonlinear frequency conversion in semiconductor heterostructures is a promising approach to the realization of compact tunable infrared sources, wavelength converters ${ }^{1}$ for optical networks, and optical processing. Asymmetric quantum wells (AQWs) have been recognized ${ }^{2-7}$ as a suitable nonlinear optical material, thanks to the high second order nonlinear coefficient and possibility of integration with semiconductor laser sources. Furthermore, it is possible to engineer the sign and the shape of the AQW nonlinearity to achieve useful frequency conversion efficiencies in waveguides. For example, reversing the AQW asymmetry can be used to optimize modal phase matching ${ }^{6}$ and to achieve quasiphase matching ${ }^{8}$ (QPM) in surface-emitting second harmonic generation (SESHG). Alternatively, selective intermixing can be used to extinguish the AQW nonlinearity and achieve quasiphase matching in copropagating SHG. ${ }^{9}$ Although the highest nonlinear coefficients are obtained at midinfrared wavelengths, where only intersubband transitions are involved, most applications require nearinfrared pumps, which involve virtual interband transitions. In the interband case, the nonlinear coefficient is expected to be smaller, ${ }^{10}$ due to the small dipole moments for interband transitions, the absence of a double resonance, the distributed nature of the transition, and a sum rule, ${ }^{10}$ which cancels out the zero order contribution in the sum over the levels. Theoretical calculations ${ }^{10-12}$ which take this sum rule into account estimate nonresonant values in the $10-20 \mathrm{pm} / \mathrm{V}$ range for the largest $\chi^{(2)}$ tensor element, namely the $(x z x)$ ( $z$ being the growth direction). Taking into account excitonic effects leads ${ }^{13,14}$ to peak values in the $200 \mathrm{pm} / \mathrm{V}$ range. The $\chi^{(2)}$ value in asymmetric coupled GaAs/AlGaAs quantum wells for frequencies above half the band gap has been measured ${ }^{15,16}$ in a reflection geometry: $\chi_{x z x}^{(2)} \approx \chi_{z x x}^{(2)}$ $\approx 15 \mathrm{pm} / \mathrm{V}$. In the transparency region for the second harmonic, the $(x z x)$ element was shown ${ }^{17}$ to be dominant in symmetric biased quantum wells, with values around 25 $\mathrm{pm} / \mathrm{V}$ for a $50 \mathrm{kV} / \mathrm{cm}$ applied field. Excitonic peaks were observed in asymmetric coupled GaAs/AlGaAs quantum

\footnotetext{
a) Also at: Laboratoire Central de Recherches, THOMSON CSF, Domaine de Corbeville, 91404 Orsay, France. Electronic mail: fiore@1cr.thomson.fr

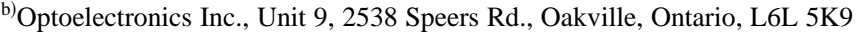
Canada.
}

wells for pumps in the band gap frequency region, ${ }^{18}$ and recently in symmetric quantum wells at half the band gap, ${ }^{19}$ although such symmetric wells should present no additional tensor elements with respect to the bulk. An excitonic peak was also observed in second harmonic generation at half the band gap of $\mathrm{ZnCdSe} / \mathrm{ZnSe}$ asymmetric coupled quantum wells. ${ }^{20}$ Nevertheless, to the best of our knowledge, no application of quantum well interband second order nonlinearity to waveguide frequency conversion has been demonstrated so far. In this letter, we experimentally demonstrate QPM SESHG in a waveguide with periodically reversed asymmetric GaAs/AlGaAs quantum wells, using the concept of "quantum well domain structures" introduced by Khurgin, ${ }^{6}$ in the geometry proposed by Harshman et al. ${ }^{8}$ By periodically reversing the orientation of the wells, a 30 -fold enhancement in the peak conversion efficiency is obtained with respect to a nonreversed sample. This geometry also allows us to measure the $\chi^{(2)}$ of the AQWs in the vicinity of the band edge. The resulting spectrum is dominated by a strong excitonic peak at half the first electron-heavy hole transition energy. These results stress the importance of seeking a compromise between nonlinearity and absorption for AQW-based frequency conversion devices.

The waveguide was designed for quasiphase matched second harmonic generation of a $1.55 \mu \mathrm{m}$ pump. The sample was grown by molecular beam epitaxy on a (100) GaAs substrate, and consists of a $0.6726 \mu \mathrm{m}$ superlattice embedded between a $2-\mu \mathrm{m}$-thick $\mathrm{Al}_{0.5} \mathrm{Ga}_{0.5} \mathrm{As}$ lower cladding layer and a $0.6 \mu \mathrm{m} \mathrm{Al}_{0.5} \mathrm{Ga}_{0.5} \mathrm{As}$ upper cladding layer. The $\mathrm{AQW}$ core layer (sample No. 1) is composed of three periods of a two domain structure. Each domain is made up of five asymmetric coupled quantum wells (as confirmed by transmission electron microscopy): $15 \AA \mathrm{GaAs} / 12 \AA \mathrm{Al}_{0.4} \mathrm{Ga}_{0.6} \mathrm{As} / 27 \AA$ GaAs/160 $\AA \mathrm{Al}_{0.4} \mathrm{Ga}_{0.4} \mathrm{As}$ (barrier); the two domains in each period have the AQW asymmetry reversed. Each domain is $0.1161 \mu \mathrm{m}$ thick, i.e., half of the second harmonic wavelength in the material. Since reversing the AQW asymmetry changes the sign of the $\chi^{(2)},{ }^{6}$ periodically reversing the asymmetry provides quasiphase matching for the $\mathrm{SH}$ wave emitted normally to the waveguide surface ${ }^{8,21}$ (see the inset in Fig. 1). A second sample (No. 2) was grown as a reference, identical to the first except that all the AQWs were oriented in the same way. The calculated first electron-heavy 


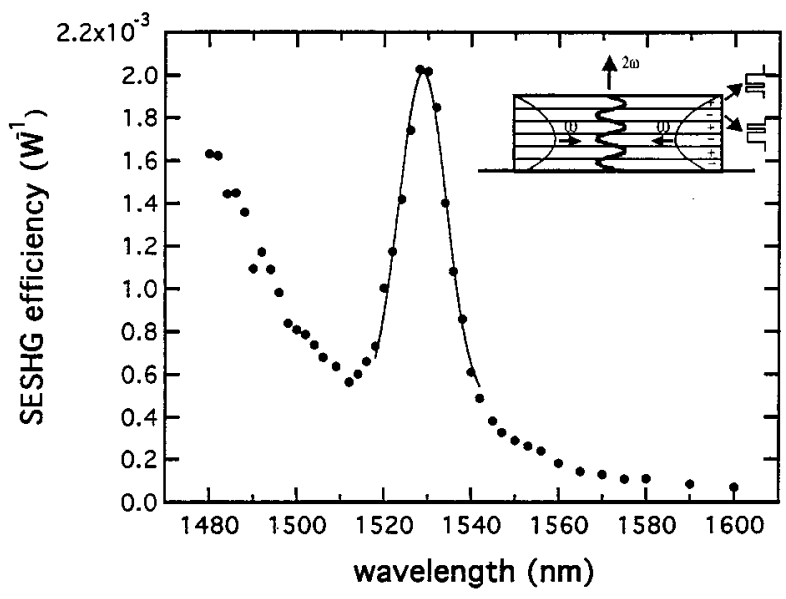

FIG. 1. Surface-emitting second harmonic generation efficiency $\left[P_{2 \omega} /\left(P_{\mathrm{TE}} P_{\mathrm{TM}}\right)\right]$ as a function of pump wavelength in sample No. 1 (reversed AQWs). Pump polarization angle is $45^{\circ}$. In the inset: principle of QPM in the vertical direction.

hole (e1-hh1) transition energy is $1628 \mathrm{meV}$ at room temperature.

Room temperature and low temperature photoluminescence were performed on the two samples using $\mathrm{HeNe}$ excitation. At room temperature, sample No. 1 has a e1-hh1 peak at $765.2 \mathrm{~nm}(1620 \mathrm{meV})$, which corresponds to the calculated value considering a $8 \mathrm{meV}$ excitonic shift. A shoulder on the high energy side indicates a electron-light hole (e1lh1) transition at $751 \mathrm{~nm}(1651 \mathrm{meV})$. The same peaks are shifted in sample No. 2 [e1-hh1: $761.3 \mathrm{~nm}(1629 \mathrm{meV})$, e1lh1: $\approx 748 \mathrm{~nm}(1658 \mathrm{meV})]$, probably due to less than $2 \AA$ difference in quantum well thickness. We also measured the low temperature photoluminescence linewidth: full width at half-maximum $\quad(\mathrm{FWHM})=7.4 \mathrm{meV} \quad$ (sample No. 1), FWHM $=7.9 \mathrm{meV}$ (sample No. 2). This rather wide linewidth is attributed to well-to-well inhomegeneity.

Ridge waveguides 4 to $10 \mu \mathrm{m}$ wide and $0.2 \mu \mathrm{m}$ deep were fabricated on the two samples using standard photolithography and chemical etching. As a pump for the second harmonic generation experiment, we used a synchronously mode-locked tunable $\mathrm{OH}: \mathrm{NaCl}$ color center laser, pumped by a $76 \mathrm{MHz}, 110$ ps mode-locked Nd:YAG laser. Typical 2 $\mathrm{mW}$ average power is end-fire coupled in the waveguide. The two counterpropagating beams necessary for the SESHG are provided by the reflection of the incident beam on the waveguide exit facet. A lens $(f=142 \mathrm{~mm})$ images the sample surface on a CCD camera. In this configuration, the near-field image of the surface emitted second harmonic (SESH) is accumulated on the CCD. The SESH appears as a periodic pattern of streaks distributed along the propagation direction. The periodicity is related to the birefringence, ${ }^{22}$ since the SESH is produced by the interaction of TE and TM beams. Indeed, in the surface emitting geometry, the only effective tensor elements are the $(x y z)$ of the bulk and the $(x z x)$ of the AQWs (the crystalline axes $x$ and $y$ are at $45^{\circ}$ angle with the TE polarization in the waveguide). Both tensor elements produce a nonlinear mixing of TE and TM modes.

We measured the SESHG efficiency as a function of wavelength. To optimize mode locking, we used the SESHG

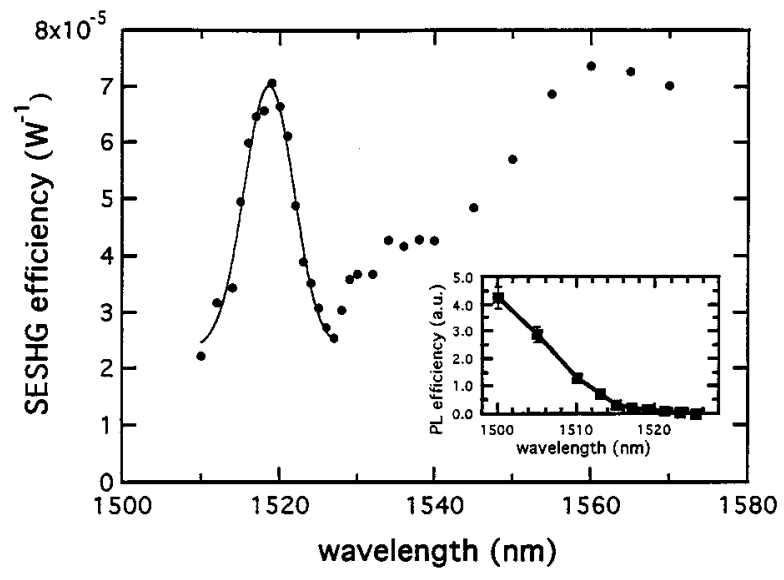

FIG. 2. Surface-emitting second harmonic generation efficiency $\left[P_{2 \omega} /\left(P_{\mathrm{TE}} P_{\mathrm{TM}}\right)\right]$ as a function of pump wavelength in sample No. 2 (nonreversed AQWs). Pump polarization angle is $45^{\circ}$. In the inset: two-photonpumped photoluminescence efficiency $\left(P_{\mathrm{PL}} / P_{\mathrm{TE}}^{2}\right)$ for a TE polarized pump as a function of pump wavelength in sample No. 2 .

nonlinear waveguide as an optical autocorrelator. ${ }^{21}$ The length of the SH streak along the guide gives the correlation of the incident and reflected part of the pulse, hence the pulse duration. We used pulse durations of about $10 \mathrm{ps}$; however, the SESHG efficiency was confirmed to be independent of pulse duration as long as the latter is shorter than twice the guide length. ${ }^{23}$ Figure 1 shows the SESHG efficiency ( $\eta$ $\equiv P_{2 \omega} /\left(P_{\mathrm{TE}} P_{\mathrm{TM}}\right), P_{2 \omega}, P_{\mathrm{TE}}, P_{\mathrm{TM}}$ being average powers $)$ in sample No. 1 (reversed AQWs) as a function of pump wavelength. Input polarization angle is $45^{\circ}$. The SESH intensity spectrum shows a large peak superposed on a continuous background, which increases towards higher energies. The peak is centered at $\lambda=1530 \mathrm{~nm}(810.3 \mathrm{meV})$, which corresponds to half of the e1-hh1 transition energy as measured by room temperature photoluminescence. The peak was fitted with a Gaussian lineshape with a FWHM=6.2 meV. The same measurement was repeated in sample No. 2 (nonreversed AQWs) (Fig. 2). Also in this case the SESH peak is centered $(\lambda=1520 \mathrm{~nm}-815.9 \mathrm{meV})$ at half of the photoluminescence e1-hh1 transition energy; for this sample, however, the peak conversion efficiency is a factor of 30 lower than in the quasiphase matched sample. The FWHM of the Gaussian fit is $3.7 \mathrm{meV}$. Subtracting the background and integrating over the SESH peak we get an enhancement factor of 47 in the quasiphase matched sample compared to the nonphase matched one. In sample No. 2 , it was impossible to measure the SESH below $1510 \mathrm{~nm}$. This is due to the fact that the low SESH signal is dominated by the photoluminescence of the AQWs pumped by two-photon absorption (TPA). In the inset of Fig. 2, we plot the TPA-pumped photoluminescence efficiency $\left(P_{\mathrm{PL}} / P_{\mathrm{TE}}^{2}\right)$ for a TE polarized input as a function of pump wavelength. As the pump energy becomes smaller than half of the e1-hh1 energy, the TPA mechanism is no longer efficient in pumping the photoluminescence.

To interpret the spectral dependence of SESHG, computer simulations of the SESHG process were performed. We model the $\chi^{(2)}$ in the reversed AQWs region as the sum of the bulk $\chi^{(2)}$ corresponding to an average composition 


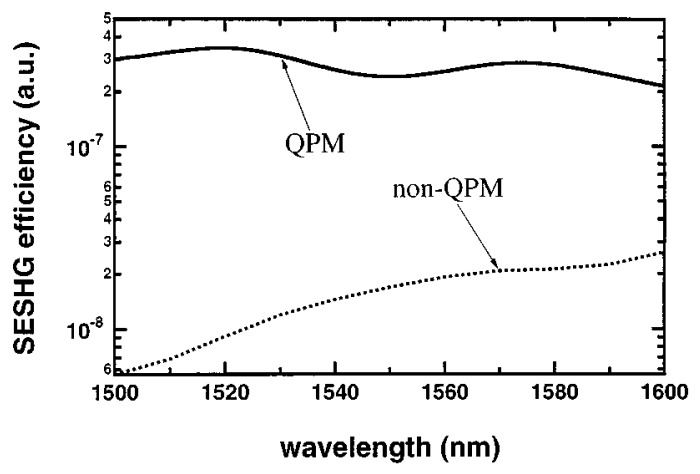

FIG. 3. Calculated SESHG efficiency for the two samples as a function of wavelength, assuming $\chi^{(2)}(\mathrm{AQWs})=0.04 \chi^{(2)}(\mathrm{GaAs})$.

$\mathrm{Al}_{0.31} \mathrm{Ga}_{0.69}$ As layer and the $\chi^{(2)}$ from the AQWs, whose sign changes in correspondance to domain reversals. For the nonreversed sample, the AQWs $\chi^{(2)}$ is constant in sign. The bulk $\chi^{(2)}$ values were interpolated from long-wavelength measured values by the use of Miller's rule. ${ }^{23}$ Local-field effects $^{24}$ are not taken into account. Figure 3 shows the calculated SESHG efficiency for the two samples as a function of wavelength, assuming a wavelength-independent $\chi^{(2)}(\mathrm{AQWs})=0.04 \chi^{(2)}(\mathrm{GaAs})$. In the QPM case, the efficiency varies slowly in the region of interest, due to the small number of QPM periods. On the contrary, the nonQPM efficiency has an oscillating behavior, related to the presence of Maker fringes (only a half-period oscillation is seen in the range shown in Fig. 3). This resonant effect explains the increase in the SESHG efficiency towards lower energies in sample No. 2. From the flat wavelength dependence of the calculated QPM efficiency, we deduce that in the QPM sample the spectral variations are due to the $\chi^{(2)}$ variation with frequency. The AQWs $\chi_{x z x}^{(2)}$ shows a clear excitonic peak and increases towards higher energies, probably due to broad high energy resonances. The calculated 35-fold enhancement due to QPM agrees well with the measured value. A comparison of the measured $\mathrm{SH}$ response with the calculated QPM efficiency shown in Fig. 3 gives an estimated peak $\chi^{(2)}$ of the AQWs of $20 \mathrm{pm} / \mathrm{V}$, assuming a $\chi^{(2)}(\mathrm{GaAs}) \approx 500 \mathrm{pm} / \mathrm{V}$ near the midgap resonance. No resonance is found in correspondance to the e1-lh1 transition (which should be at $1502 \mathrm{~nm}$ ). This confirms that light holes contribute a lower nonlinear coefficient, as predicted by theory. ${ }^{10,12}$ We attribute the smaller FWHM of the excitonic peak in the non-QPM sample to the combined effect of phase mismatch and absorption, which isolate the contribution of the top few wells, thus reducing the effective inhomogeneous broadening.

In conclusion, we have reported observation of quasiphase matched surface emitting second harmonic genera- tion in coupled asymmetric quantum well waveguide. This geometry greatly enhances the conversion efficiency and allows to isolate AQWs contribution from the bulk. The measured spectrum shows a large excitonic peak. This confirms that excitonic effects strongly enhance the quantum well susceptibility in the midgap frequency region. These results are promising for the realization of frequency conversion devices based on AQW waveguides. We also demonstrated use of this device as a optical picosecond autocorrelator.

This work was partially financed by an ECAMI travel grant. One of the authors (A.F.) also acknowledges financial support from an EC-TMR grant. The authors thank Dr. Sylvain Charbonneau (IMS/NRC) for measuring photoluminescence spectra, Professor Emmanuel Rosencher, Dr. Vincent Berger, Dr. Borge Vinter (Thomson CSF/LCR), Professor Gaetano Assanto (III ${ }^{\text {rd }}$ University of Rome), and Professor Francesco De Martini ( ${ }^{\text {st }}$ University of Rome) for fruitful discussions.

${ }^{1}$ S. J. B. Yoo, C. Caneau, R. Bhat, M. A. Koza, A. Rajhel, and N. Antoniades, Appl. Phys. Lett. 68, 2609 (1996).

${ }^{2}$ M. K. Gurnick and T. A. D. Temple, IEEE J. Quantum Electron. QE-19, 791 (1983).

${ }^{3}$ M. M. Fejer, S. J. B. Yoo, R. L. Byer, A. Harwit, and J. S. Harris, Phys. Rev. Lett. 62, 1041 (1989).

${ }^{4}$ E. Rosencher and P. Bois, Phys. Rev. B 44, 11315 (1991).

${ }^{5}$ F. Capasso, C. Sirtori, and A. Y. Cho, IEEE J. Quantum Electron. 30, 1313 (1994).

${ }^{6}$ J. Khurgin, J. Appl. Phys. 64, 5026 (1988).

${ }^{7}$ E. Rosencher, A. Fiore, B. Vinter, V. Berger, P. Bois, and J. Nagle, Science 271, 168 (1996).

${ }^{8}$ P. J. Harshman and S. Wang, Appl. Phys. Lett. 60, 1277 (1992).

${ }^{9}$ M. W. Street, N. D. Whitbread, C. J. Hamilton, B. Vogele, J. S. Aitchinson, D. C. Hutchings, J. H. Marsh, G. T. Kennedy, and W. Sibbett (unpublished).

${ }^{10}$ J. Khurgin, Phys. Rev. B 38, 4056 (1988).

${ }^{11}$ L. Tsang, S. L. Chuang, and S. M. Lee, Phys. Rev. B 41, 5942 (1990).

${ }^{12}$ A. Fiore, E. Rosencher, B. Vinter, D. Weill, and V. Berger, Phys. Rev. B 51, 13192 (1995).

${ }^{13}$ H. Kuwatsuka and H. Ishikawa, Phys. Rev. B 50, 5323 (1994).

${ }^{14}$ R. Atanasov, F. Bassani, and V. M. Agranovich, Phys. Rev. B 50, 7809 (1994).

${ }^{15}$ S. Janz, F. Chatenoud, and R. Normandin, Opt. Lett. 19, 622 (1994).

${ }^{16}$ X. H. Qu, H. Ruda, S. Janz, and A. J. Springthorpe, Appl. Phys. Lett. 65, 3176 (1994).

${ }^{17}$ A. Fiore, E. Rosencher, V. Berger, and J. Nagle, Appl. Phys. Lett. 67, 3765 (1995).

${ }^{18}$ Y. L. Xie, Z. H. Chen, D. F. Cui, S. H. Pan, D. Q. Deng, Y. L. Zhou, H. B. Lu, Y. Huang, S. M. Feng, and G. Z. Yang, Phys. Rev. B 43, 12477 (1991).

${ }^{19}$ H. Ito, F. Minami, K. Yoshida, and K. Inoue, J. Lumin. 66\&67, 493 (1996).

${ }^{20}$ V. Pellegrini, A. Parlangeli, M. Borger, R. D. Atanasov, F. Beltram, L. Vanzetti, and A. Franciosi, Phys. Rev. B 52, R5527 (1995).

${ }^{21}$ R. Normandin, S. Letourneau, F. Chatenoud, and R. L. Williams, IEEE J. Quantum Electron. 27, 1520 (1991).

${ }^{22}$ D. Vakhshoori, M. C. Wu, and S. Wang, Appl. Phys. Lett. 52, 422 (1988).

${ }^{23}$ Y. Beaulieu (unpublished).

${ }^{24}$ A. Liu, Opt. Commun. 119, 191 (1995). 